\title{
THE USE OF TECHNOLOGY IN CUSTOMER RELATIONSHIP MANAGEMENT (CRM)
}

\author{
M Viljoen, JA Bennett, AD Berndt \& CR van Zyl, University of Johannesburg South Africa
}

\begin{abstract}
Relationships have increased in importance in the field of business and marketing in the recent past. This importance can be linked to the changing nature of competition and technological developments. In this context, the question that has been posed is how these two factors affect the development of relationships. In the case of competition, relationships can serve as the basis for competitive advantage, while technology serves as the enabler of relationship building.

The focus of this article is a theoretical discussion of the technological developments and their application in the CRM context in the implementation of CRM strategy. The article examines the nature of CRM and the components of the various technological CRM systems as well as the specific types of systems that can be used in relationship building, concluding with a discussion of specific technological tools in the CRM context.
\end{abstract}

Keywords and phrases: CRM; Interactive CRM; Predictive CRM; e-CRM

\section{INTRODUCTION}

The area of Relationship Marketing (RM) and Customer Relationship Management (CRM) continues to receive attention both in the literature and in practice, with research and websites that discuss the uses and benefits of CRM to the organisation (Xu \& Walton, 2005; Xu, Yen, Lin \& Chou, 2002). This attention has been accompanied by technology developments that have been applied in the area of CRM.

The purpose of CRM is the building of relationships in order to affect customer acquisition, retention, loyalty and profitability (Swift in Ngai, 2005:283), resulting in the development of 1:1 relationships with these customers. The importance of technology and its use in CRM is in the increased use of these technologies to establish relationships and develop loyalty and retention among existing customers. The effective use of CRM systems can assist in the organisation's relationship-building activities while also contributing to the profitability of the organisation.

Studies have been carried out into diverse aspects of information technology, including from a knowledge management perspective (Stefanou, Sarmaniotis \& Stafyla, 2003), from a strategic perspective (Bull, 2003) and from the effect that it has on various customer aspects such as loyalty (Taylor \& Hunt, 2002; Lee-Kelley, Gilbert \& Mannicom, 2003).

The article will attempt to consolidate the theoretical basis for the use of specific technology in the implementation of CRM strategy by organisations while examining the possible tools in CRM systems.

The article will begin by examining the link between technology and CRM, and then proceed to examine specific technologies and their application within CRM.

\section{THE NATURE OF CRM}

CRM can be defined as an organisational approach that seeks to understand and influence customer behaviour through meaningful communications in order to improve customer acquisition, retention, loyalty and profitability (Swift in Ngai, 2005:583). It may also include the termination of the relationship, should the customer prove to be unprofitable to the organisation (Du Plessis, Jooste \& Strydom, 2001:257). A technology-related perspective of CRM is formulated by Hamilton (in Law, Lau 
\& Long, 2003:51) in that CRM is described as the process of storing and analysing of large amounts of data that provides insight into customer behaviour. This in turn enables the organisation to treat customers differently based on the exhibited behaviour.

Despite these definitions, there appears to be little agreement on the specific nature of Relationship Marketing (RM) and CRM, with CRM becoming a buzzword and reflecting a number of different perspectives (Luck \& Lancaster, 2003:214).

The success of a CRM strategy can be seen in the specific goals that are set for the strategy. Some of the goals that can be set include retaining existing customers, improving customer lifetime value, improving customer satisfaction, and customer share and customer loyalty (Xu \& Walton, 2005:959; Luck \& Lancaster, 2003:214). Customer satisfaction is regarded as the customer's attitude towards the organisation, product or service (Piercy, 2003: 29). Customer satisfaction is influenced by the specific product or service features and the customer's perceptions of service quality (Zeithaml \& Bitner, 2003:87). Satisfaction is identified as a crucial component in loyalty and customer commitment, and hence organisational profitability.

\section{The Importance of CRM to an Organisation}

The primary focus of any CRM strategy is to enable the organisation to create and retain profitable customers (Swift in Ngai, 2005:583). Most strategies evolve around three aspects, namely customer profitability, customer acquisition and customer retention, due to the reduced costs associated with retaining customers rather than obtaining new customers (Peck, Payne, Christopher \& Clark, 2004:47).

\section{Customer profitability}

Customer profitability tracks the financial performance of customers with respect to all the costs associated with a transaction (Gordon, 1998:29). Profitability is determined in the light of the lifetime value of the customer to the organisation, taking into account the income and expenses associated with each customer over time (Gordon, 1998:146). The tracking of profitability is made more accurate through the use of technology.

\section{Customer acquisition}

A great deal of time and money is spent on attracting new customers, but few resources are focused on retaining customers. The cost of attracting a new customer is estimated to be five times the cost of keeping a current customer happy (Kotler, 1997:47). The cost of attracting a new customer is often higher than the customer's lifetime value with the organisation (Kotler, 1997:47). It is clear from the above that an emphasis on customer acquisition without focusing on the resulting relationship with the customer is a waste of money to the organisation.

\section{Customer retention}

Retention involves ensuring that the customer remains loyal to the organisation and, in so doing, both parties are able to receive substantial benefits (Zeithaml, Bitner \& Gremler, 2006:185). Organisations can increase their profitability by between $20 \%$ and $125 \%$ if they boost their retention rate by five per cent (Peck et al., 2004:47). Customers who receive excellent service remain loyal and provide free advertising by talking about the organisation's products and services (Reichheld \& Sasser, 1990:107). An organisation with a primary focus on customer retention should have information about the customer retention rate and the aspects that affect possible customer defection and migration (Peck et al., 2004:49).

\section{TECHNOLOGY AND CRM}

Building relationships with customers requires data on the customer. If data is to be used, it has to be clean and timely, and the impression is gained that organisations have extensive data on their 
customers (Anon, 2002; Abbott, 2001:184). It has been suggested that organisations are not ready for the implementation of CRM as their data is not good enough (Abbott, 2001:183). In research conducted in the UK in 2000, none of the organisations had data that was completely up to date, clean and usable or a fully implemented CRM strategy (Abbott, 2001:184).

\section{TECHNOLOGY AND CRM - THE CRM ECOSYSTEM}

Technological developments continue to affect the organisation and the marketing of its products and services. These technological applications include the computer (specifically the World Wide Web) and mobile telephone technology. CRM needs to be seen as more than just technology with the technology being regarded as the enabler of the CRM strategy (Xu, Yen, Lin \& Chou 2002: 445).

In using technology, a number of technology applications can be identified that are used in the development of CRM strategy (Xu \& Walton, 2005; Zaayman, 2004; Chen \& Popovich, 2003; META Group, 1999). Three main components of CRM systems can be identified, as illustrated in Figure 1.

Figure 1: Technology applications of CRM

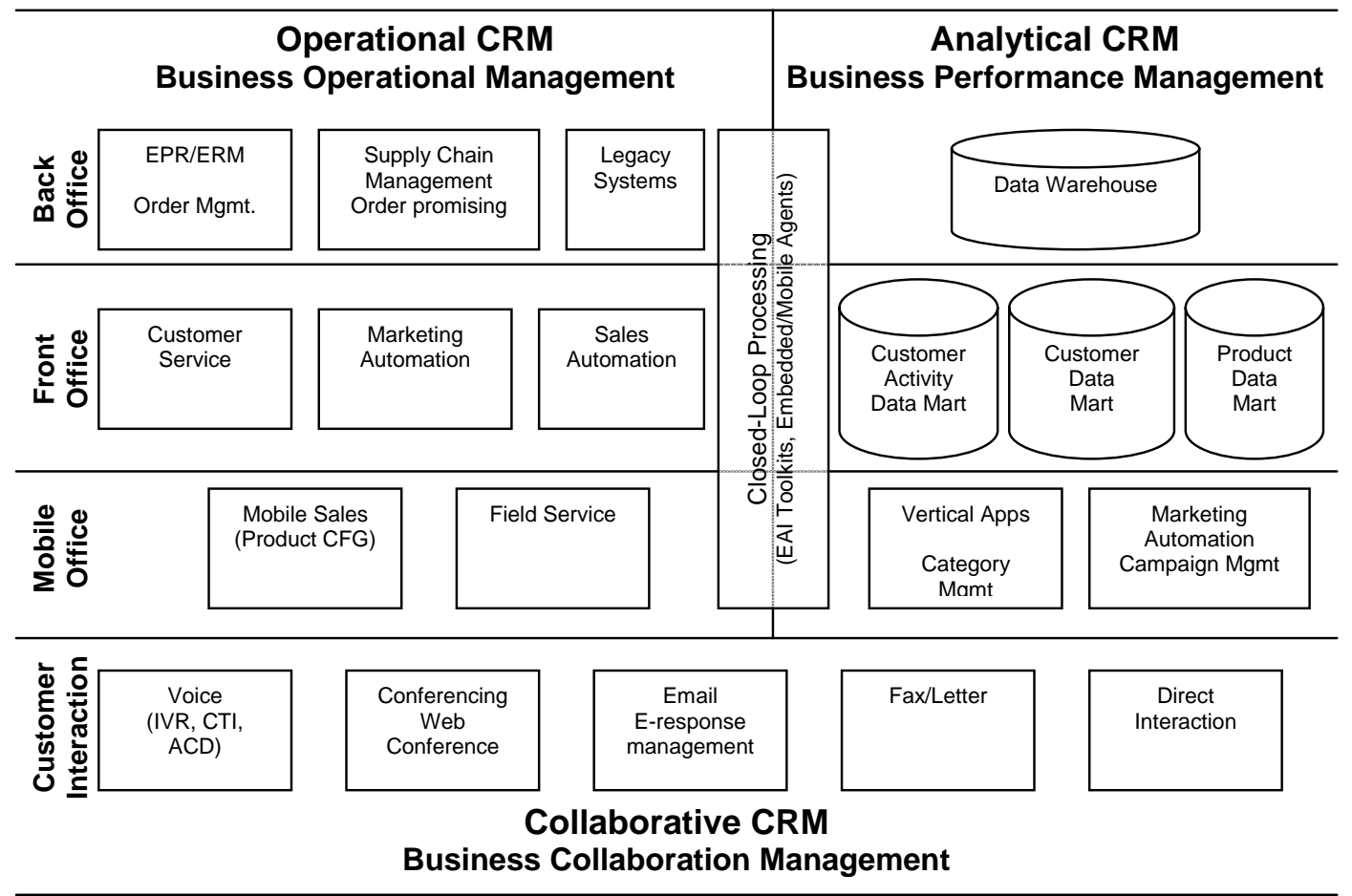

Source: Adapted from: Shahnam, 2000:3

Operational CRM includes customer-facing applications such as sales force automation, enterprise marketing automation and customer service and support (Chen \& Popovich, 2003:672). Customer call centres are also a component of operational CRM, and have been identified as the dominant aspect in CRM systems (Xu \& Walton, 2005:960; Anon, 2000). All interactions with the customer are recorded, enabling the organisation to gather data on the customer and thus track the customer (Xu \& Walton, 2005:961). Despite call centres being the dominant form of operational CRM, in research conducted in the UK, it was found that less than $40 \%$ of organisations had implemented a call centre (Abbott, 2001:184). 
Analytical CRM analyses the data that has been created through operational CRM to build a picture of the customer. Analytical CRM includes the capturing, storage, extraction, processing, interpretation and reporting of customer data stored in data warehouses (Xu \& Walton, 2005:961). This enables the organisation to examine customer behavioural patterns in order to develop marketing and promotional strategies (Xu \& Walton, 2005:961). In research conducted in the UK, 25\% of the organisations surveyed indicated that they used analytical CRM (Xu \& Walton, 2005:960). This would appear to indicate that the primary use of CRM systems is operational in nature (Xu \& Walton, 2005:960).

Collaborative CRM uses new and traditional communication technologies to enable customers to interact with the organisation (Meta Group, 1999). Collaborative CRM allows a better level of response to customer needs by involving all the members of the supply chain such as suppliers or other partners (Xu \& Walton, 2005:961). It also involves channel strategies or any function that provides a point of interaction (or touch point) between the customer and the channel (Shahnam, 2000:3).

A further category of CRM systems identified by Chaudbury and Kuiboer (2002) in Xu \& Walton, 2005:960 is that of e-CRM. e-CRM makes it possible for the organisation to have as much contact as possible through all communication channels, notably through the Internet and Intranet. e-CRM is thus a web-centric approach to customer contact (Xu \& Walton, 2005:961). This Internet support takes on the form of presales, services and post-sales support (Sterne in Feinberg, Kadam, Hokama \& Kim, 2002:470). The Internet makes it possible to have frequent contact with the customer, and so keep their databases as pure as possible while developing better customer relationships (O'Leary, Rao \& Perry, 2004:338). It has also been suggested that the value of the Internet can be seen in the quicker flow of information and more consistent communications that can result from its use (Luck \& Lancaster, 2003:216). Using the Internet enables CRM to become more interactive, affecting the relationships that are developed (Xu et al., 2002:445). It has been suggested that while the Internet is used for promotional purposes, its interactive capabilities have not been used to their fullest extent (O'Leary et al., 2004: 338). It is further suggested by Taylor \& Hunt (2002:453) that the consequences of e-CRM may not assist in attaining the CRM goals as identified for a specific strategy.

\section{SPECIFIC TECHNOLOGY APPLICATIONS WITHIN CRM}

The development of CRM technology can be viewed from the perspective of the level of information technology applied in building customer relationships. Four stages can be identified in this development process (Stefanou, Sarmaniotis \& Stafyla, 2003:623). These four stages are illustrated in Figure 2. 
Figure 2: The phases in the development of CRM

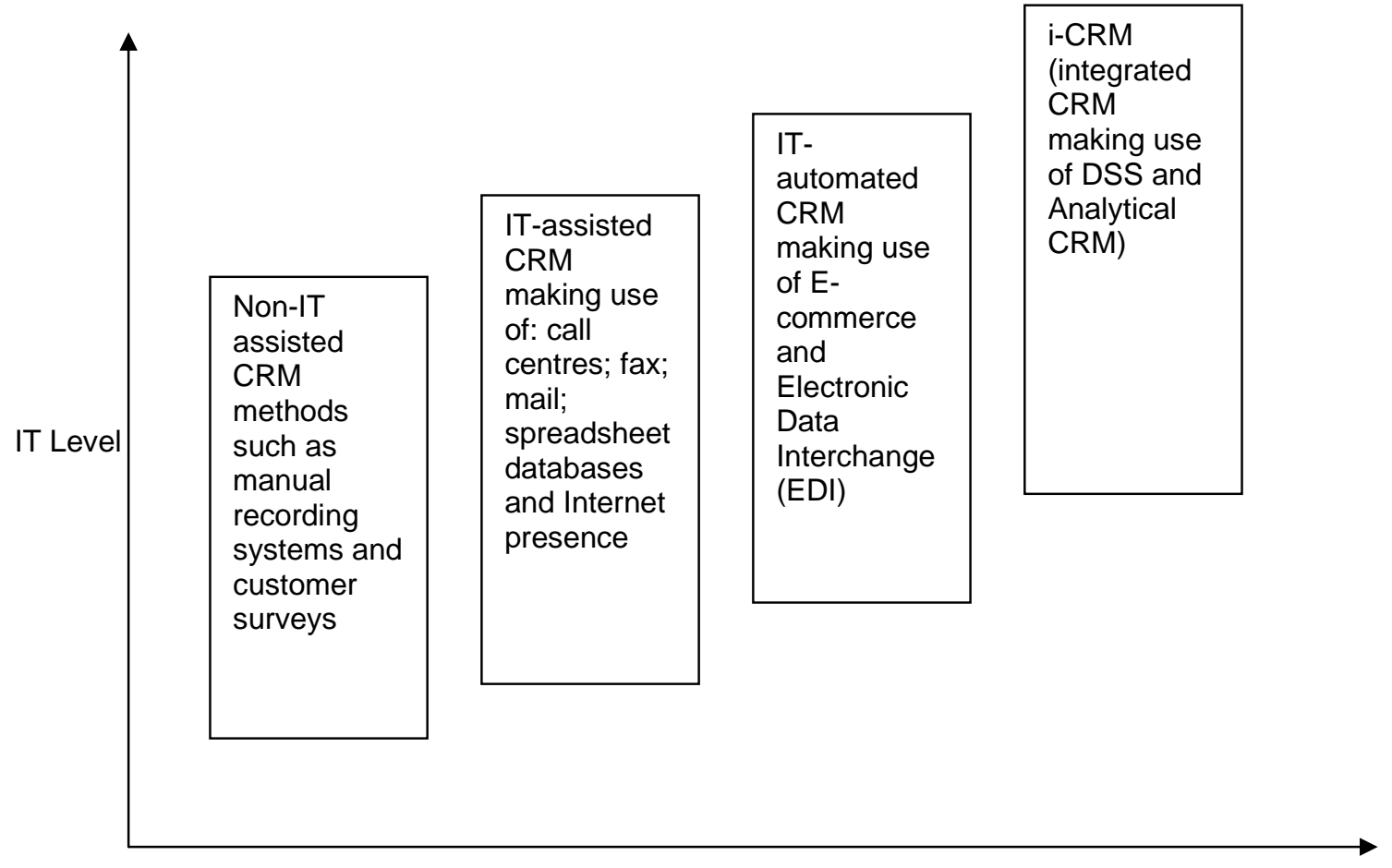

Stages Of Implementation

Adapted from: Stefanou, Sarmaniotis \& Stafyla, 2003:623

From the above discussion, the following proposition can be formulated:

Proposition 1: The customers of organisations that have a greater incorporation of technology in their CRM strategies will be more satisfied than those with a lower degree of technology.

\section{PREDICTIVE CRM}

According to Crowder (2001), predictive CRM is the discipline of getting to know your customers by performing complex analyses on data about them, and it is rapidly changing the way in which companies make operational and strategic decisions about the procurement, production, marketing and sales of products and services. According to Harney (2003), predictive analytics is a subset of data mining that enables you to derive new insights or new information from existing information.

The existing information that is used to predict future customer activities concerns the particular behaviour that can be associated with specific customer groups (Xu \& Walton, 2005:965). The existing information is thus used to identify trends that can affect the organisation.

Predictive analytics through the examination of current behaviour can indicate the following to the organisation:

- Possible lucrative up-selling opportunities as an organisation is able to determine which consumers are candidates for additional products/services. 
- Customer churn rates. A churn rate refers to the extent to which customers withdraw their patronage from an organisation. Through predictive CRM, customer action can be tracked, making it possible to determine whether customers will withdraw their patronage.

- The best sales channel(s) to reach customers. According to Blumstein in Harney (2003), you want to know which channel is the best channel, which combination of channels is the best, and how much communication in each of those channels is optimal to the relationships.

- Identify their most profitable customers and then deliver differentiated levels of service to them.

- Better targeted promotional materials to boost sales and improve customer service can be sent to them. The example of Fingerhut is cited where predictive CRM was used to send promotional brochures to customers based on the nature of the customer behaviour and customer segmentation (rather than the nature of the promotion), resulting in the optimisation of customer value (Crowder, 2002; Bull 2003:593).

Predictive CRM thus enables the organisation to determine future behaviour, which can increase the effectiveness of the strategy. Predictive CRM enabled a Japanese-based computer and software reseller to increase its profits by $200 \%$ (and attain an $18 \%$ growth in sales) as it made use of a recommendation engine based on their existing personal profiles (Shearer, 2004).

Proposition 2: The use of predictive CRM techniques increases the effectiveness of the CRM strategy for the organisation.

\section{INTERACTIVE CRM (ICRM)}

ICRM is the integration of instant communication with captured and analysed website customer data, and it has evolved to help customers remain in contact with the organisation. ICRM is used to improve customer care, to build longer term relationships, to improve the use of website productivity, and to increase the integration of web sales and customer care (Tanoury, 2002). As it makes use of communication technologies, it can be regarded as collaborative CRM.

According to Trepper (2002), current website customers demand instant access to the companies with which they do business and expect each person they contact to have full knowledge of their account. Web-based e-commerce activities enable interactive CRM (ICRM), where customer queries can immediately be resolved online in real time. This leads to the faster resolution of customer doubts and online experiential difficulties, thereby increasing customer satisfaction and loyalty.

The fundamental goal of ICRM is therefore to create greater customer loyalty, sales and satisfaction, and to provide a rich source of customer knowledge that can be used to gain a deeper understanding of customers in order to facilitate the provision of fully personalised service. For example, during a live interactive web chat session, a customer service representative (CSR) may uncover specific customer preferences and needs (e.g. the need for a greater range of products and information about competing products and their relative prices available on the Website). This new knowledge can be integrated with other web CRM knowledge to tailor the website better and according to customer needs. If the above-mentioned need is characteristic of an important and profitable targeted customer segment, website content and offerings can be adjusted accordingly to improve the customer's satisfaction, thereby increasing loyalty as well as current and future revenue streams.

The knowledge gleaned from ICRM can therefore be integrated with other Website CRM data (held in an integrative database for conversion into valuable knowledge), which can improve sales opportunities and customer relationships, and hence profitability. Interactive web customer service through ICRM increases the lifetime value of a customer by escalating future sales through repeat visits. The organisations behind these websites use a full range of electronic CRM solutions to provide immediate interactive communications and knowledgeable customer care (Trepper, 2002).

A study carried out by Accenture in 2001 indicated that the level of customer satisfaction is higher in the B2B environment than in the B2C environment (Taylor \& Hunt, 2002:453). 
Proposition 3: Organisations that implement ICRM effectively will have a higher degree of customer satisfaction than organisations that do not implement ICRM

\section{TOOLS IN CRM}

A main component of any CRM strategy entails the facilitation of two-way interaction between individual customers and the organisation (external communications) about every aspect of the relationship, enabling the organisation to adjust its strategy, including product design, customer service and channel preferences.

According to Gubser (2001), some of the interactive technologies that provide interactive customer communications and care include:

- Intelligent email: Email remains an important method of customer contact for more than $70 \%$ of online businesses (Gubser, 2001). However, in research conducted by Bradshaw \& Brash (2001), $85 \%$ of websites invited email contact with the organisation yet $32 \%$ replied to the email sent by the customer (2001:523). This research further found that response times to emails varied between 40 minutes and four days. The development of artificial intelligence means that simple and frequently asked questions (FAQs) can be answered by a computer without the customer's knowledge of the fact that the message was actually computer-generated as opposed to humanresponded (Gubser, 2001). The faster and more effective responses to customer queries that are enabled via intelligent email significantly reduce customer time costs and enable the more efficient resolution of their problems. This can, in turn, increase customer satisfaction and subsequent loyalty and retention rates.

- Collaborative chat: If customers have questions about a product or shipping details, a live collaborative chat function enables them to click on a live customer service icon that brings up a chat box. If customers have shopped on that specific website before, and registered with their user name when logging on, they may be addressed by name by the Customer Service Representative (CSR). Should the CSR have access to all the customer's history with the organisation, they will be able to interact with the customer in a more meaningful way (Gubser, 2001).

- Self-help: Self-help consists not only of traditional FAQs, but also intelligent FAQs (where expert search systems can interpret a customer question to find an answer that a keyword search might not locate) and virtual agents or bots can chat with customers, answer their questions and make suggestions almost as effectively as a live person (such bots are equipped with a learning algorithm that enables them to improve the accuracy of their responses with each customer contact they experience; queries that cannot be handled are diverted to a live agent) (Gubser, 2001). Such self-help features increase customer satisfaction through the quick and efficient resolution of queries, and they collect important customer information that can be fed into and aggregated in the website-linked CRM database to serve customer needs better, uncover preference trends, and improve relationships and loyalty.

- Telephony: Computer telephony integration (CTI) can be incorporated as web pages can now be equipped with call-back buttons that can, when clicked on, open a window in which a customer can provide a phone number where he/she can be reached for questions or other service provision. The request for a call may also be directed to a specific CSR who is familiar with the goods or services advertised on a particular web page, thereby increasing the probability of a sale and the acquisition of a new customer (Gubser, 2001).

- VoIP: VoIP is a technology whereby an organisation's Local Area Network (LAN) or Wide Area Network (WAN) can be used to transfer both data and voice. This essentially means that an organisation no longer needs to use physical phone lines in order to communicate to the outside world. This enables the organisation (and their representatives) to speak directly to customers through speakers or headphones. A VolP salesperson can use web pages to show new products or services while conversing with the customer about their various attributes. This can increase customer acquisition and retention due to the interaction while affecting the overall website effectiveness. 
These tools make it easier for the parties to make contact with each other, which contributes to the development of the customer relationship.

Proposition 4: The implementation and provision of interactive communication technologies enhance the quality and frequency of organisation-customer communication, thereby increasing the success of the CRM strategy.

\section{MANAGERIAL IMPLICATIONS}

Consistency of service is crucial in the success of technologically-driven strategies. Having CRM systems within the organisation does not mean that the organisation is guaranteed profitability or other types of success (Bradshaw \& Brash, 2001:529). The organisation has to have the basics of business such as customer service and quality products functioning properly as the technology cannot resolve these issues (Bradshaw \& Brash, 2001:529). In fact, it has been proposed that there is greater pressure on customer service due to the implementation of CRM systems (Xu et al., 2002:443).

The customer plays an integral role in the CRM systems used by organisations. Without data on their behaviour, or the willingness on their part to supply this data to the organisation, the organisation will be limited in its implementation of these systems. One of the reasons for the resistance of consumers is the privacy issue regarding their information (Franzak, Pitta \& Fritsche, 2001:631). A high degree of technology within the organisation will be incorporated within the CRM strategies, and the organisation will be able to integrate diverse data from customers. Better quality information affects the interaction with the customer as well as customer satisfaction levels.

The development of CRM systems has resulted in the development of various packages that can be used in CRM strategies. There is not only the question of the integration of these packages within the IT systems of the organisation, but there is also the question of the cost of the package and its implementation, which the organisation has to address. The cost has to be viewed from an investment perspective that will yield results in the long term, rather than the short term (Xu et al., 2002:447). A further challenge facing management is the integration of computer systems within the organisation as a whole. There are occasions where customers are required to submit information that has already been made available to the organisation, much to their frustration (Bradshaw \& Brash, 2001:525; Anon, 2002).

Should this integration of information systems not take place, it will be perceived by customers in their interactions with the organisation. The customer may receive numerous copies of the same information from different groupings within the organisation, which conveys a poor image of the organisation. This will impact on the quality and frequency of the communication that is sent to the customer, affecting the success of the CRM strategy.

It is not only the integration of the systems that is required within organisations, but also the nature of the systems being used. The use of advanced technology which includes predictive CRM and ICRM has the potential effect of helping the organisation determine future behaviour and making the necessary adjustments in their operations. It further enables the organisation to interact with the customer and determine necessary changes on the part of the organisation. This has the effect of increasing the effectiveness of the organisation and of the CRM techniques that form part of their strategy.

\section{CONCLUSION}

Successful CRM strategy implementation is the goal of any organisation that is seeking to build relationships with customers. To facilitate this, CRM systems hold a great deal of promise in enhancing these activities. Despite questionable implementation to date, predictive CRM, interactive $\mathrm{CRM}$ and interaction technologies in this area can be some of the major contributors in this regard, which can provide the organisation with a competitive edge in the marketplace. It must be ensured that the CRM systems that are selected are appropriate for the organisation and used purposefully in order to gain the maximum benefits from them, namely the attainment of CRM goals. 
It is envisaged that the research will be conducted initially as an exploratory study to determine the nature of the technology being used in CRM strategies as well to investigate the use of both predictive CRM and ICRM and the effects that these may have on the quality of interactions between the organisation and the customer.

\section{REFERENCES}

Abbott J. 2001. Data data everywhere - and not a byte of use? Qualitative Market Research: An International Journal, 4(3): 182-192.

Anon. 2002. What went wrong with CRM? [Online] Available from: http://www.itanalysis.com/article_pf.php?articleid=3310 [Accessed: 2005/11/22].

Anon. 2000. Computer Telephony Integration (CTI) [Online] Available from: http://www.itanalysis.com/article_pf.php?articleid=1119 [Accessed: 2005/11/22].

Bradshaw D \& Brash C. 2001. Managing customer relationships in the e-business world: how to personalise computer relationships for increased profitability. International Journal of Retail and Distribution Management, 29(12): 520-529.

Bull C. 2003. Strategic issues in customer relationship management (CRM) implementation. Business Process Management, 9(5): 592-602.

Chen IJ \& Popovich K. 2003. Understanding customer relationship management (CRM) People, process and technology. Business Process Management Journal, 9(5): 672-688.

Crowder H. 2002. Predictive Customer Relationship Management [Online] Available from: http://www.dieselbrain.com/resources/montreal02.ppt [Accessed: 2005/11/20].

Crowder HP, Dinkelacker J \& Hsu M. 2001. Predictive Customer Relationship Management: Gaining Insights about Customers in the Electronic Economy [Online] Available from: http://www.dmreview.com/master.cfm?NavID=198\&EdID=3020 [Accessed: 2004/04/10).

Du Plessis PJ, Jooste CJ \& Strydom JW. 2001. Applied Strategic Marketing. Sandown: Heinimann.

Feinberg RA, Kadam R, Hokama K \& Kim I. 2002. The state of electronic customer relationship management in retailing. International Journal of Retail and Distribution Management, 30(10): 470481.

Franzak F, Pitta D \& Fritsche S. 2001. Online relationships and the customer's right to privacy. Journal of Consumer Marketing, 18(7): 631-641.

Gordon IH. 1998. Relationship marketing: new strategies, techniques and technologies to win the customer you want and keep them forever. Toronto: John Wiley \& Sons.

Gubser L. 2001. Enhancing Online Customer Loyalty - New Tools and New Traps [Online] Available from: http://www.tmcnet.com/cis/oeA0201.htm [Accessed: 2004/04.10].

Harney J. 2003. Predictive Analytics: Forecasting Future Trends from Existing Data [Online] Available from:

http://www.kmworld.com/publications/magazine/index.cfm?action=readarticle\&article_id=1404\&public ation_id=1 [Accessed: 2004/04/10].

Kotler P. 1997. Marketing management: analysis, planning, implementation, and control. New Jersey: Prentice Hall International. 
Law M, Lau T \& Wong YH. 2003. From customer relationship management to customer-managed relationship: unravelling the paradox with a co-creative perspective. Marketing Intelligence \& Planning, 21(1): 51-60.

Lee-Kelley L, Gilbert D \& Mannicom R. 2003. How e-CRM can enhance customer loyalty. Marketing Intelligence \& Planning, 21(4): 239-248.

Luck D \& Lancaster G. 2003. E-CRM: customer relationship marketing in the hotel industry. Managerial Auditing Journal, 18(3): 213-231.

META Group. 1999. META group urges "ecosystem" Approach to customer relationship management [Online] Available from:

http://www.domino.metagroup.com/presshome/nsf(OldPressRelease)/39670AB70FC730EB [Accessed: 2004/05/10].

Ngai EWT. 2005. Customer relationship management research (1992-2002). Marketing Intelligence \& Planning, 23(6): 582-605.

O'Leary C, Rao S \& Perry C. 2004. Improving customer relationship management through database/Internet marketing. European Journal of Marketing, 38(3/4): 338-354.

Peck H, Payne A, Christopher M. \& Clark M. 2004 Relationship Marketing - Strategy and Implementation. Burlington: Butterworth Heinemann.

Piercy NF. 2003. Market-led Strategic Change. Amsterdam: Butterworth-Heinemann.

Reichheld FF \& Sasser WE. 1990. Zero defections: quality comes to service. Harvard Business Review, September- October: 105-111.

Shearer C. 2004. One-to-One CRM with Predictive Analytics [Online] Available from: http://www.crmbuyer.com/story/36059.htm [Accessed: 2005/11/22].

Shahnam E. (2000). The Customer Relationship Management Ecosystem [Online] Available from: http://www.metagroup.com [Accessed: 2002/05/20].

Stefanou CJ, Sarmaniotis C \& Stafyla A. 2003. CRM and customer-centric knowledge management: an empirical research. Business Process Management, 9(5): 617-634.

Tanoury D. 2002. Web-Enabled Customer Relationship Management [Online] Available from: http://www.dmreview.com/whitepaper/WID478.pdf [Accessed: 2004/03/10].

Taylor SA \& Hunter GL. 2002. The impact of loyalty with e-CRM software and e-servcices. International Journal of Service Industry Management, 13(5): 452-474.

Trepper CH. 2002. Tools Help Personalize the Customer Experience [Online] Available from: http://www.informationweek.com/812/pricrm.htm [Accessed: 2004/10/03].

Xu M \& Walton J. 2005. Gaining customer knowledge through analytical CRM. Industrial Management \& Data systems, 105(7): 955-971.

Xu Y, Yen DC, Lin B \& Chou DC. 2002. Adopting customer relationship management technology. Industrial Management \& Data systems, 102(8): 442-452.

Zaayman P. 2003. Functional requirements of e-CRM solutions for the South African SME Sector. Unpublished M Phil disseration. Johannesburg: Rand Afrikaans University. 
VILJOEN M

BENNETT JA

BERNDT AD

VAN ZYL CR
The Use of Technology in Customer Relationship Management (CRM)

Zeithaml VA, Bitner MJ \& Gremler DD. 2006. Services Marketing Integrating across the firm. $4^{\text {th }}$ Edition. Boston: McGraw-Hill.

ZeithamI VA \& Bitner MJ. 2003. Services Marketing Integrating customer focus across the firm. $3^{\text {rd }}$ Edition. Boston:McGraw-Hill. 